\title{
RECORDANDO A COMTE
}

Inés Tardel $M$.

\author{
L'Amour pour principe, et \\ L'Ordre pour base; \\ le Progrès pour but'.
}

Una de las primeras cosas que aprende el alumno de Sociología al ingresar a la carrera es que el nombre de la disciplina elegida se debe a Auguste Comte, filósofo francés quien vivió a mediados del siglo XIX (1798-1857). Generalmente, este conocimiento perdura a través de los años, pero, la mayoría de las veces, olvidando sus méritos de haber sistematizado a la Sociología como disciplina científica, determinándole un objeto propio de estudio, adecuándole un método, el positivo, y destacando los dos aspectos más importantes de la realidad social: el estático y el dinámico.

Comte nació en Montpellier, en el sur de Francia, en un período de crisis societal, de cambios profundos y de secuelas de otros cambios anteriores, como lo fueron la revolución industrial (con el invento de las máquinas a vapor y de coser), la revolución francesa y la Universidad napoleónica, el rápido avance de las ciencias naturales, el régimen del "laissez faire" en lo económico, transformaciones que paralelamente conllevaron la secularización y la racionalización del pensamiento.

La sociedad del siglo xIX ya no se presentaba como en la Edad Media como un reflejo de la voluntad de Dios que dispone un determinado orden social. La sociedad moderna había generado una crisis en la convivencia social y la sociedad, en ese momento, era un problema y un quehacer que le correspondía asumir a los hombres. Era el siglo de las luces; era el siglo de la razón. Respondiendo a esta necesidad, empezó la Sociología a configurarse como ciencia, en la primera mitad

Comte, Auguste, Système de Politique Positive ou Traité de Sociologie, Tome Cuatrième, Ed. Georges Crès et Cie., Place de la Sorbonne, Paris, 1912, $1^{\text {a }}$ pág. 
de este siglo, coincidiendo con el desarrollo de otras ciencias sociales como la Antropología, Psicología, Economía y Ciencia Política. Así, la Sociología nace después de la revolución francesa, en la que triunfa la clase media y, en vísperas de la aparición de otra clase social, los obreros.

Desde pequeño, Comte demostró habilidades matemáticas y literarias, las que lo llevaron a ganar, a los 16 años de edad, una plaza en la Escuela Politécnica de París. Desde entonces empezó a demostrar su interés por los problemas societales ${ }^{2}$. Ingresó al círculo del conde Henry de Saint Simon (1760-1825), de quien llegó a ser, al cabo de poco tiempo, su amigo y secretario. Saint $\operatorname{Simon}^{3}$ fue uno de los primeros pensadores sociales y socialistas utópicos que buscaba el mejoramiento de la sociedad impactada por los efectos destructores de la revolución francesa. La situación en París se caracterizaba por ser el centro de corrientes mesiánicas, tecnocráticas y socialistas, correspondientes a tradiciones intelectuales contradictorias, las cuales se orientaban hacia dos polos: al programa positivista que pretendía acelerar el proceso de cambio de la sociedad a través del conocimiento científico, y hacia el programa idealista, con su concepción orgánica de la sociedad y contraria al cambio social planificado.

Saint Simon ejerció una profunda influencia en el joven Comte y, entre los años 1817 y 1823 , trabajaron en estrecha colaboración, al extremo de no poderse distinguir, en ocasiones, cuál era el aporte de cada uno. De esa época es la obra "Plan de las Operaciones Científicas necesarias para la Reorganización de la Sociedad" 4 publicada en 1822, en la que se plantea la necesidad de una ciencia teórica de la sociedad, cuyo objeto de estudio no podía ser otro que la sociedad misma, y, su objetivo era la búsqueda y encuentro de las leyes naturales inmutables del progreso. En esta obra se desarrolla la Ley de los Tres Estadios.

A esta nueva disciplina "positiva" se la denomina "Física Social", la cual, como toda rama del conocimiento, pasaría por un proceso evolutivo de tres etapas: la teológica, la metafísica y la positiva, proceso destinado a alterar el devenir histórico. Este punto será retomado más adelante.

Durante este período de trabajo conjunto, Comte y Saint Simon combinaron sus análisis teóricos, marcados por un profundo intelectualismo, con un activismo igualmente profundo, derivado de sus deseos de reorganizar la sociedad. Pero esta unión se quebró al tomar posiciones intelectuales diferentes.

Comte continuó trabajando en la nueva disciplina, profundizando su ley de los tres estadios, y desarrollando un esquema conceptual y teórico en el que se incluía

2 Raison, Timothy (Ed.). The Founding Fathers of Social, Science collection Penguin Books Ltd. England, Cap. "Auguste Comte", de Julius Gould, p. 35, año 1969.

3 Timasheff, Nicolás, La Teoría Sociológica.

4 Raison, Timothy, Op. cit., pp. 33 y siguientes. 
el concepto "organicista", de esencia socialmente conservadora de la sociedad, combinando de esta manera la postura positivista con la idealista-organicista, que, hasta ese momento, eran opuestas. Como dice Martindale ${ }^{5}$, Comte "dio al Socialismo una respuesta conservadora". Pero, lo importante es que Comte logró construir un modelo teórico lógicamente coherente, el cual permitió analizar la sociedad en su totalidad y en sus partes, explicando su organización y transformación en una perspectiva evolutiva, con intención de universalidad, independientemente si estemos o no de acuerdo con ella. Esta forma de abordar el conocimiento de la sociedad fue similar al de otros pensadores de aquella época, como por ejemplo, Marx y Engels, contemporáneos de Comte $y$, que como él, fueron a un tiempo teóricos y reformadores.

En su obra "Curso de Filosofía Positiva", compuesta por 6 volúmenes publicados entre los años 1830 y 1842, recopiló su serie de conferencias privadas sobre filosofía positiva, en las que desarrolla, y de manera especial en la Lección 437 , Tomo iv (1839), su modelo teórico, en el que se identifican tres principios básicos ${ }^{6}$ :

1. La primacía del todo sobre las partes. Para comprender y explicar un determinado fenómeno social es necesario situarlo en el contexto social global al que pertenece, al igual que para explicar un fenómeno o proceso orgánico es necesario considerarlo en relación con el organismo entero. Este principio lo aplica tanto al análisis del "orden espontáneo de las sociedades humanas" o Sociología Estática como también al análisis de la evolución de las sociedades o Sociología Dinámica.

Al tomar como referencia a la Historia para entender y explicar la sociedad de una época determinada, Comte está concibiendo una Sociología comparada inserta en el marco general de la Historia Universal.

2. La directriz de la historia humana está dada principalmente por el progreso de los conocimientos. Conocer no es interpretar el mundo, ni construir un sistema de conceptos metafísicos generales, sino que descubrir las leyes que rigen el mundo para modificarlas en provecho propio. Las relaciones del hombre con los otros hombres y con el mundo dependen de sus conocimientos de la naturaleza y de la sociedad. Los modos de conocimiento constituyen el elemento dominante de la historia, ya que para Comte existiría una coherencia lógica entre el estado de los conocimientos y la organización social o la "civilización", como dice este autor. El progreso de la civilización estaría regido por leyes.

3. El hombre es idéntico en todas partes y en todos los tiempos. Este principio lo deriva de la constitución biológica y del sistema cerebral del hombre. La sociedad, entonces, debe evolucionar en todas partes de idéntico modo y en el mismo sentido, pasando a un tipo más avanzado de sociedad, en un modelo de ascensión lineal.

Martindale, Don, La Teoria Sociológica, Ed. Aguilar, Madrid, 1968, pp. 72 y 73.

Rocher, Guy, Introducción a la Sociologia General, Ed. Herder, Barcelona, 1977, pp. 194 a 204. 
Para Comte, la Sociología tiene por objeto de estudio a la sociedad misma, considerándola como una trama espiritual, como cultura, buscando sus elementos componentes y las leyes que regulan sus conexiones. El conocimiento de estas leyes permite la predicción de los fenómenos sociales, con las limitantes que derivan de la complejidad propia de este tipo de fenómenos.

Por ello, el fundamento de las ciencias estaba en las matemáticas, permitiendo el acceso a los aspectos abstractos de todos los fenómenos. Sobre ellas Comte ubica a la mecánica, en especial la mecánica de los cuerpos celestes estableciendo las conexiones de las formas espaciales, pobres de contenido pero precisas y muy generales. Luego, siguen las ciencias orientadas al estudio de las conexiones entre las cosas en movimiento: la Física, Química y, a continuación, la Biología. Por último, "coronando el edificio de la sabiduría humana", estaría la Sociología, la más compleja y específica de todas. Desde este momento denomina Sociología a la nueva disciplina.

Comte divide el objeto de estudio de la Sociología en dos grandes rubros: la estática social y la dinámica social, términos que hace sinónimos con los de orden y progreso, respectivamente.

1. La estática social o teoria de las instituciones ${ }^{7}$, como la denomina, pone de relieve el "consentimiento universal" u orden social en un determinado momento. La Sociología trata de encontrar las leyes que regulan ese orden social, el cual depende de muchos factores, tales como la raza, el clima, los instintos de los individuos, pero principalmente depende de las ideas, ya que son estas últimas las promotoras del cambio.

La sociedad la concibe como una unidad orgánica. No es exactamente igual a un organismo, pero se le parece. Los órganos societales son las instituciones, siendo las fundamentales la religión, la familia, la educación y la político-económica. Las instituciones son definidas como las más pequeñas unidades sociales potencialmente autosuficientes.

La institución religiosa, es de suyo importante por cuanto a través de ella la humanidad llegará a una unión consensual moral cuando se logre la necesaria correlación entre los elementos de la sociedad. El estado de armonía plena, propia de la existencia humana, tanto colectiva como individual, es lo que caracteriza a la religión. Esta institución está constituida por aspectos intelectuales objetivos y por aspectos morales subjetivos. Es por ello que la religión se expresa a la vez como razonamiento y sentimiento.

La religión, en su fase positiva, ya alcanzada, se caracteriza por el amor, el orden y el progreso. Comte propone que siempre, durante la existencia, a nivel

Lauber, Jean, Auguste Comte, sociologie, Presses Universitaires de France, Paris, 1963, première partie, pp. 3 a 74 . 
individual o societal, debe aplicarse la fórmula sagrada de los positivistas: “El amor por principio, el orden por base, y el progreso por Norte" 8 .

Al hablar de la institución económica, Comte se refiere particularmente a la "propiedad", a lo contingente, a diferencia del tratamiento que da a la institución religiosa. Este autor busca las leyes económicas a través de la acumulación y trasmisión de la riqueza, con sus correspondientes influencias sociales y políticas.

Pero, la institución básica de la sociedad es la familia. En la sociedad identifica tres niveles o dimensiones: el individuo, la familia y la sociedad misma.

La familia cumple un papel moral en la sociedad fundamentalmente a través de la mujer, a quien Comte le asigna roles con respecto a la pareja, a los hijos y parientes, referidos a la trasmisión de principios y valores morales.

Societalmente, la familia es importante, pues de ella se desprenden otras formas sociales, ya sean tribus o naciones, diciendo este autor textualmente: "Podemos representarnos a toda la raza humana como el desarrollo gradual de una sola familia" ${ }^{9}$, enfatizando así la importancia del estudio de esta institución social. La familia es el nexo entre la Biología y la Sociología, considerando el hecho biológico de la reproducción, hecho que es trascendido al derivar conexiones de consanguineidad, de las que a su vez derivan otras formas sociales.

Así, la unidad real del estudio sociológico es la sociedad, ya que es superior al organismo individual y abarca a toda la humanidad. La convivencia es producto de ideas comunes que hacen converger los intereses y actividades de los individuos, de manera constante, a la participación en el desarrollo colectivo como una disposición espontánea. Sin embargo, Comte no considera al individuo en el estudio sociológico porque un sistema debe estar constituido sólo por fenómenos homogéneos. Por esto, la unidad social básica para el estudio de la sociedad, es la familia.

Con respecto a la institución política, más bien la identifica como orden político, plantea que éste es natural porque no puede existir ninguna sociedad sin gobierno, el cual, a su vez, deriva del deseo generalizado de mandar de algunas personas y del deseo de no tomar decisiones por si mismas de muchas otras, es decir, espontáneamente se facilitaría la cooperación como la subordinación y la inclinación al gobierno o autoridad.

En la sociedad estarían actuando en forma simultánea tres tipos de fuerzas diferentes: la material, la intelectual y la moral, las que en su conjunto darian la dinámica a la estructura societal. Estas fuerzas o poderes se basarían, respectivamente, en la fuerza, la razón y el afecto.

El poder material se concentraría en los ricos, el poder intelectual en los sabios,

$8 \quad$ Lauber, Jean, Op. cit., p. 14.

9 Martineau, Harriet, The Positive Philosophy of Auguste Comte, 2 volumenes, Londres, J. Chapman, 1853. Traducida y Resumida de "Cours de Philosphie positive", 6 volúmenes, Paris, 1830-1842, por Harriet Martineau, citado por Martindale, op. cit., p. 73. 


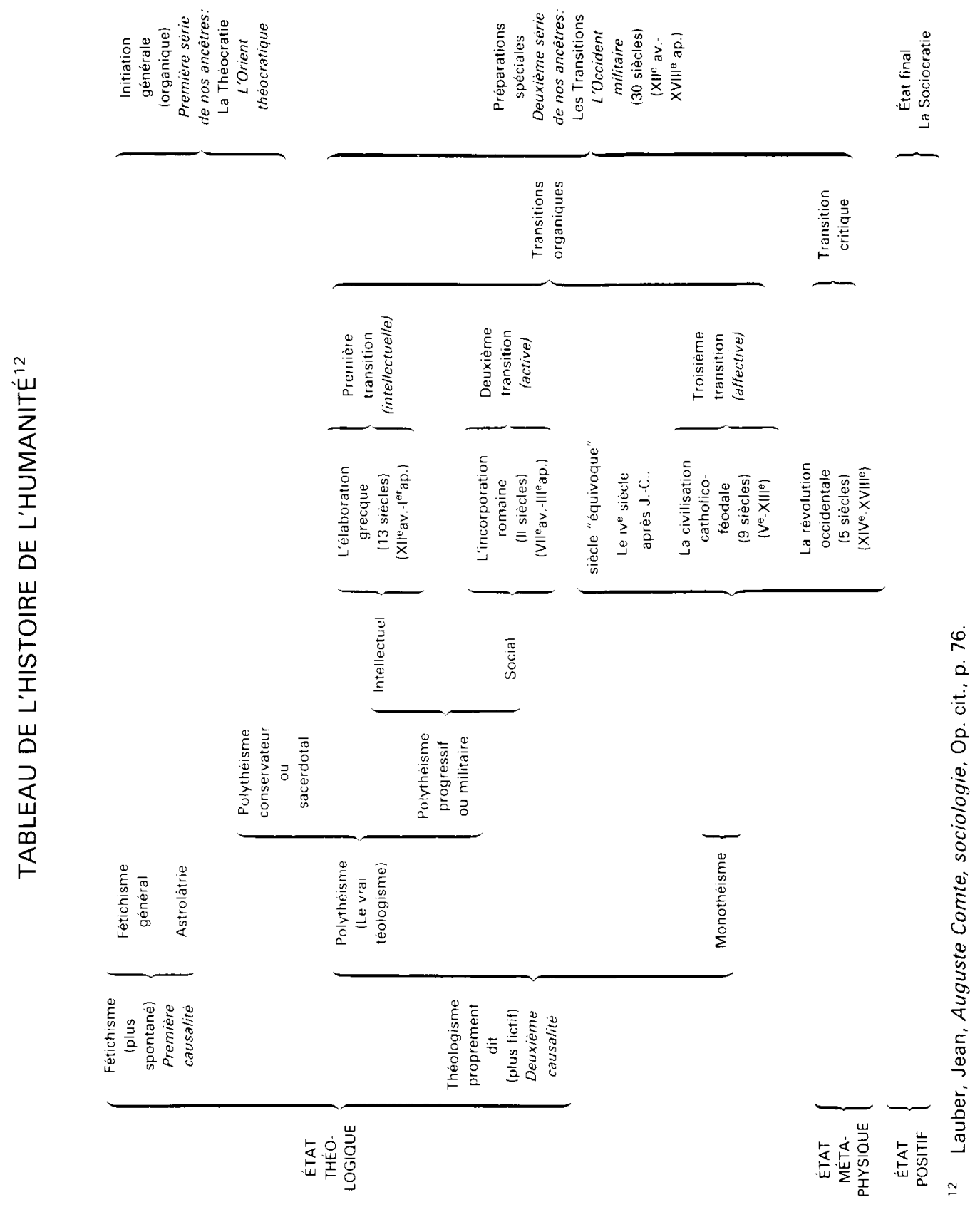


y el poder moral en las mujeres. Los dos últimos poderes se combinarían constituyendo un poder único, el cual, bajo el calificativo de espiritual, estaría destinado a modificar el poder material.

La complejidad e integración de la estructura social se apoya en la división del trabajo, en la que se encuentran relaciones de solidaridad, cooperación y de subordinación, con las variaciones determinadas por las diferencias naturales de los individuos.

En suma, repito, la estática social pone de relieve el consentimiento universal que tienen entre sí las diferentes partes que forman el orden social. De allí la importancia de observar y descubrir las leyes que regulan el orden social, el cual está correlacionado con el orden de la inteligencia y, por lo tanto, la importancia de estudiar paralelamente el surgimiento de las ideas para conocer el cambio de este orden social.

2. La dinámica social o filosofía de la historia es la historia social de la humanidad: La Sociología es la ciencia encargada de encontrar la ley que explique el desarrollo de la humanidad. Esa ley es la que nos dice que la humanidad ha pasado por tres estadios: el teológico, el metafísico y el positivo. Este último habría partido desde 1822, fecha en que se publicó la obra "Plan de las Operaciones Científicas Necesarias para la Reorganización de la Sociedad", a la que ya nos referimos en las primeras páginas de este artículo.

La ley de los tres estadios establece el orden de sucesión y las características principales de los tres estadios, es decir, de las tres formas por las que pasan sucesivamente todas las concepciones humanas, tanto individuales como colectivas, a partir de la infancia hasta la edad viril. El estadio inicial es el "teológico", caracterizado por la búsqueda de las causas y la ficción de las divinidades, el estadio final, etapa positiva o científica, que ha cambiado la búsqueda de las causas por la determinación de las leyes y el conocimiento relativo; $y$, el estadio intermedio o "metafísico", que es un estadio equivocado, que ha sustituido las divinidades por las entidades, constituyendo una especie de estadio teológico degenerado, uniendo a su antecesor con su sucesor, porque el destruir las ficciones teológicas hace posible el aparecimiento de las primeras manifestaciones del estadio positivo.

Con respecto a la evolución intelectual, también necesariamente considera el paso por las tres etapas en orden sucesivo: la primera, teológica o ficticia, es siempre provisoria; la segunda, metafísica o abstracta, es transitoria, y la tercera, positiva o científica, es definitiva y demostrativa. Estos tres estadios sucesivos de la inteligencia se corresponden con los modos consecutivos y evolutivos de las variaciones propias de las formas de la actividad: la conquista, la defensa y el trabajo. De esta correlación natural fundamental resulta la explicación de las etapas naturales de la humanidad. Su larga infancia que se relaciona con la Antigüedad, esencialmente teológica y militar; su adolescencia con la Edad Media, la 
cual fue metafísica y feudal; y, su madurez, apenas apreciable en la época comtia$n a$, es necesariamente positiva e industrial.

En la página siguiente se incluye un gráfico elaborado por Comte acerca de la Historia de la Humanidad a través de la ley de los tres estadios.

Igualmente, todo conocimiento humano atraviesa por tres etapas sucesivas y evolutivas, correspondiendo cada una de ellas a las etapas en que se dividiría la Historia. Así, cada etapa histórica poseería un carácter temporal y espiritual diferente, de acuerdo al avance del conocimiento, tal como a continuación se explicita:

a) Estadio teológico y militar: El hombre, en su búsqueda de la explicación de lo sorprendente, encuentra la respuesta en lo religioso en el recurso a la divinidad. Las concepciones teóricas de este estadio llevan el sello de lo sobrenatural. La imaginación está por sobre la razón. La sociedad es de tipo militar, ya que en los orígenes de la humanidad era necesario un control fuerte para lograr y mantener el orden social requerido para el paso del nomadismo al culto de la tierra y para satisfacer necesidades de las personas y de las colectividades ${ }^{10}$.

La sociedad militar al ser acientífica por su espíritu teológico, era agrícola, y su unidad social fue la familia, predominando un tipo de orden doméstico. La fase inicial del estado teológico es fetichista al darle vida y acción a las cosas. Comte subdividió la etapa teológica en cinco subetapas, de acuerdo al proceso evolutivo del conocimiento y del progreso. A la subetapa fetichista le siguieron la politeísta (imperios orientales), la politeista intelectual (Grecia), la monoteísta social (Roma), y la monoteísta defensiva (el mundo católico).

b) Estadio metafísico y juridico: El conocimiento se caracteriza por respuestas abstractas e ideas que intentan explicar la naturaleza de las cosas. Estas abstracciones metafísicas reemplazan a las sobrenaturales del estadio anterior, permitiéndose a la observación modificar, aunque de manera limitada, a la imaginación. Es una etapa de transición.

La sociedad se caracteriza por la distinción entre el poder espiritual y el temporal, siendo este último el que termina por imponerse sobre el primero, consolidándose la autoridad civil, cuyos poderes, basados en la ley, aumentan. Es la sociedad legista en la que las nociones de Estado y Patria adquieren importancia. Se amplian las funciones y el poder del Estado, los que se delegan en Ministros y diplomáticos. Se traspasa una parte de la autoridad de los reyes.

Esta sociedad de los legistas destruye la unidad de la sociedad teocrática, desorganizándola como consecuencia de las crisis y revoluciones. Es un período de crítica y discusión. Esta sociedad se asienta sobre la nación.

Para Comte, este período era necesario en este proceso evolutivo, ya que el estadio positivo no podía suceder directamente al teológico.

Rocher, Guy, Op. cit., pp. 198 y siguientes. 
c) El estadio positivo e industrial: El hombre renuncia a conocer la naturaleza intima de las cosas y las causas primeras y finales. Los conocimientos le aseguran at hombre el dominio y control del universo. Este es el estadio superior del conocimiento, al que corresponde una sociedad de tipo industrial, ya que las ciencias positivas aplicadas al orden natural transforman las condiciones laborales apareciendo la industria. Así, la ciencia desarrolla la acción racional y las relaciones entre los hombres se organizan sobre bases industriales.

La industria, dice Rocher ${ }^{10}$, es, "en cierto modo, la punta de lanza de la mentalidad positiva, cuya influencia alcanzaría finalmente a la totalidad de la sociedad", lo cual tendría que provocar un cambio radical de la organización social y, en forma paralela, una transformación profunda de las mentalidades.

Comte plantea que aunque la sociedad industrial esté en sus comienzos, es posible predecir las principales características que tendrá en el futuro, señalando que la mentalidad positiva será la que domine la sociedad industrial, orientada a la producción industrial, cuyo aumento será consecuencia de la concentración de los trabajadores en las ciudades, en torno a las fábricas.

En el proceso evolutivo todo se va transformando, pero las desigualdades sociales, por ser inherentes a la estructura societal, se mantendrán. Dos nuevos grupos de personas accederán al poder: los industriales organizando y orientando su acción hacia el trabajo y los sabios, en especial los "sociólogos", quienes tendrían el poder político y su acción se orientaría a la ordenación de la sociedad.

Como todo proceso de cambio, habría períodos de trastornos sociales, crisis y revoluciones, pero serán fases transitorias porque a medida que el espíritu positivo se difunda, que la industria se desarrolle por el progreso técnico, y que la acción de sabios y sociólogos ejerza influencia, la paz internacional y social progresará.

La ignorancia y la falta de moral social serían las causas principales de los conflictos. Pero gracias al conocimiento positivo, las masas comprenderán las exigencias de la vida social y los imperativos de la historia. Las creencias positivas, y en especial la Sociología, serían las promotoras de una nueva moral: la religión positivista, una especie de catolicismo sin cristianismo, la cual lograría la unión moral de toda la humanidad.

Comte, en sus años maduros, se dio cuenta de que las ideas, para que fuesen eficaces en la sociedad, debían ser respaldadas por instituciones, y así fue como ideó para la nueva ciencia de la sociedad una organización imitando a la Iglesia Católica, a la cual debía sustituir. La religión positivista de Comte se basaba en el conocimiento y en el método científico, no reconociendo ninguna metafísica ni poder divino y trascendente, eligiendo como principio rector, el amor al prójimo; como fundamento, el orden; $y$, como finalidad, el progreso. 


\section{CONCLUSIONES}

Comte fue el primero en sistematizar y exponer una Sociología científica, aunque, como todos sabemos, estaba demasiado influida por el modelo de las ciencias naturales e inserta en una postura filosófica, situación esta última que lo llevó a orientar su "ciencia positiva" hacia el estudio de la humanidad más que a la sociedad misma.

La separación del objeto de estudio de la Sociología en estática y dinámica, separación que hasta hoy no se ha superado, Comte la planteó con fines analíticos, pero nunca como una separación de la ciencia en dos partes, sino que se trata de dos aspectos de una teoría. Así, mientras la Sociología dinámica estudia las leyes de la evolución de las circunstancias sociales, la Sociología estática estudia sus conexiones, representando para la práctica política, el progreso y el orden, respectivamente.

Comte intuyó el rol profesional del Sociólogo actual, al ofrecer sus servicios al zar Nicolás I para asesorarlo para reorganizar su sociedad. Comte entendió la Sociología como una ciencia aplicada, como un instrumento de reforma social, pero también y simultáneamente como una ciencia pura, racional y positiva, verdaderamente científica. 